\title{
Egg-shell $\mathrm{Ni} / \mathrm{Al}_{2} \mathrm{O}_{3}$ Catalyst for the Hydrogenation of Mixed $\mathrm{C}_{5}$ Alkenes
}

\author{
Jiř́i Kolena , Gabriela Št’ávová, Pavel Morávek, Kamil Štěpánek \\ Unipetrol, Center for Research and Education (UNICRE), Czech Republic
}

Copyright $\bigcirc 2017$ by authors, all rights reserved. Authors agree that this article remains permanently open access under the terms of the Creative Commons Attribution License 4.0 International License

\begin{abstract}
A process of $\mathrm{Ni} / \mathrm{Al}_{2} \mathrm{O}_{3}$ eggshell type catalyst preparation has been developed in laboratory scale. Active catalysts with high Ni content, in which the active metal is concentrated in a very thin layer below the particle surface, were prepared by this process. Wet impregnation of carrier particles with a solution of inorganic $\mathrm{Ni}$ salt in organic solvent, in particular ethanol and acetone, was the basic principle of the preparation method. Catalysts with a maximum Ni content of 20.9 mass \%, concentrated into a layer of thickness of $770 \mu \mathrm{m}$ were prepared when ethanol was used as the solvent, while $15.4 \% \mathrm{Ni}$ maximum concentration and $622 \mu \mathrm{m}$ layer thickness were achieved when acetone was used as the solvent. The catalysts prepared were characterized by following analytical methods: XRD, BET, Raman spectroscopy and EDS. The catalysts activities were tested in the gas phase $\mathrm{C}_{5}$ olefins hydrogenation. Despite the lower Ni content, the catalyst impregnated by Ni nitrate, dissolved in acetone was characterized by higher activity in comparison with the catalyst impregnated by ethanol solution.
\end{abstract}

Keywords Catalyst, Nickel, Eggshell, Hydrogenation, Alumina, Impregnation

\section{Introduction}

Hydrogenation of $\mathrm{C}_{4}$ rafinate or $\mathrm{C}_{5}$ fraction is a widespread method of primary processing of these side products streams from the production of ethylene by steam cracking. This fraction contain around $50 \%$ of alkenes and their hydrogenation, which is most common way of their upgrading, is a strongly exothermic process. A catalyst for this process has to be stable and characterized by high selectivity in a broad temperature interval.

Suitable catalysts for olefins hydrogenation should contain at least one of transition metals, belonging to group VIII of periodic table, as the active component, monometallic or bimetallic systems being most frequently used for this purpose [1-5]. Ni is often used as the main metal component but sometimes it takes part of a catalyst modifier $[4,5]$. Catalysts impregnated in entire volume of particles, which are easy to prepare, are widely used in industrial hydrogenation processes. Ni containing catalysts are very active therefore the internal diffusion limitation can be a real problem affecting heat exchange and the reaction selectivity. As hydrogenation is a strongly exothermic reaction, and $\mathrm{Ni}$ tends to catalyze $\mathrm{C}-\mathrm{C}$ bond hydrogenolysis (hydrocracking), particles overheating beyond control can take place at higher temperatures [3]. Minimizing of all negative effects of internal diffusion is the main reason for utilization of eggshell type catalysts, the catalyst manufacture economy playing also certain role in case of noble metals are utilized as active components.

The egg-shell catalysts are generally prepared by impregnation - drying method though some alternative methods have also been described [7]. The speed of adsorption of a precursor of the active component onto the support surface, the speed of diffusion of impregnation solution into a support particles and also the solvent evaporation rate are the main parameters deciding whether an egg-shell concentration profile is achieved or not $[6,8-$ 10]. Some attempts were made to describe relations between preparation conditions and the active component concentration profile by a mathematical model $[9,10]$. A model was developed, which accounted for convective flow in the liquid phase, multicomponent diffusion of the metal in the liquid phase, metal adsorption on the porous support and heat transfer [9]. Another type of diffusion-deposition model of the impregnation system with consideration of the effect of the drying process was also developed for the impregnation of spherical alumina pellets with $\mathrm{Ni}$ ammonia complex solution [10].

It was one of the conclusions of theoretical studies $[9,10]$ that high viscosity solvents used in the impregnation process can limit the metal diffusion into the carrier pellets and thus contribute to the formation of an egg-shell metal concentration profile. It was verified by Silva et.al. [11] who used glycerol in impregnation of $\Upsilon$-alumina by Ni-Fe salts solution by which an egg-shell catalyst was successfully 
prepared.

The preparation of $\mathrm{Ni} / \mathrm{Al}_{2} \mathrm{O}_{3}$ egg-shell type catalyst was also patented [1]. The preparation method consisted in impregnation of $2 \mathrm{~mm}$ alumina particles by $3 \mathrm{M}$ solution of $\mathrm{Ni}(\mathrm{NO})_{3}$ in tetrahydrofurane. The catalysts prepared, containing 5-15 wt. \% of $\mathrm{Ni}$, were used for pyrolysis gasoline hydrogenation.

It is worth mentioning that some alternative methods for preparing egg-shell catalysts have been tested. Wen et al. presented a method based on precipitation of layered double hydroxides on the surface of $\Upsilon$-alumina spheres by using a diluted ammonia solution as precipitator [7]. The hydroxides were then converted into oxides by calcination at $450^{\circ} \mathrm{C}$. $\mathrm{NiO}$ containing egg-shell catalyst was thus prepared.

A method of preparation of $\mathrm{Ni} / \gamma$-alumina egg-shell type catalysts with high metal content was developed in the frame of this study. The goal was to develop a simple and cheap method of the preparation of industrially utilizable catalyst. The method is based on impregnation of alumina particles with concentrated solution of inorganic $\mathrm{Ni}$ salt in selected volatile organic solvents. The method takes advantage from the fact that volatile organic solvents can be quickly evaporated so there is a chance to concentrate Ni to a very thin layer below the particle surface.

\section{Experimental}

\section{Catalyst Preparation}

Catalysts were prepared by wet impregnation of alumina spheres ID $5 \mathrm{~mm}$ (Sasol) with $\mathrm{Ni}\left(\mathrm{NO}_{3}\right)_{2} .6 \mathrm{H}_{2} \mathrm{O}$ solution. The main reason for the choice of this Ni salt was its excellent solubility in organic solvents which made it possible to use high metal content solution. Acetone and ethanol were used as the organic solvents. They were supposed to be suitable for the preparation of catalysts with thin impregnated layer, because of their volatility.

The mass ratio between carrier and impregnation solution was 1:8. The contact time of carrier and the solution was 3 to $5 \mathrm{~s}$. Impregnated carrier was separated from the solution and dried at the temperature equal to boiling point of the solvent used. This procedure was repeated at least three times to achieve desired Ni concentration. After that, dry catalyst particles were annealed in the air at programmed temperature to convert $\mathrm{Ni}$ salt to $\mathrm{Ni}$ oxide. The temperature increase velocity was of $0.4^{\circ} \mathrm{C} / \mathrm{min}$., the final temperature, which was maintained for $300 \mathrm{~min}$, was of $500^{\circ} \mathrm{C}$. During this period of time, $\mathrm{Ni}$ was converted almost completely to $\mathrm{NiO}$ which could have been easily reduced to active $\mathrm{Ni}$. The reduction of the oxidized form of the catalyst was performed in-situ, immediately before testing, at the temperature of $450^{\circ} \mathrm{C}$ in a stream of pure hydrogen, the reduction time being $24 \mathrm{~h}$. The catalysts prepared and reported to in the frame of this study are surveyed in Table 1.
Table 1. A survey of $\mathrm{Ni}$ catalysts prepared and conditions of their preparation

\begin{tabular}{|c|c|c|c|}
\hline Catalyst name & Ni conc. (wt. \%) & Solvent & $\begin{array}{c}\text { Ni in impreg. } \\
\text { solution (wt \%) }\end{array}$ \\
\hline VA10B & 7.4 & Acetone & 3 \\
\hline VA20 & 15.4 & Acetone & 3 \\
\hline VE15 & 10.9 & Ethanol & 4 \\
\hline VE15B & 20.9 & Ethanol & 4 \\
\hline
\end{tabular}

\section{Catalysts Characterization}

$\mathrm{Ni}$ content in catalysts was determined by ICP method after decomposition of the solid sample by sulphuric acid by the method of calibration curve according to ISO 1185 . Agilent 725 device was used for this purpose.

The thickness of the layer impregnated by $\mathrm{Ni}$ was determined by the EDS (Energy-dispersive X-Ray spectroscopy) method. For this purpose (EDS), Bruker Quantax 200, equipped with a detector XFlash SDD 5010 was used.

XRD was performed on a D8 Advance Eco (Bruker) diffractometer using $\mathrm{Cu}-\mathrm{K} \alpha$ radiation, scanned in $2 \theta$ interval from 5 to $70^{\circ}$ with a rate of $0.02 \%$, voltage of $40 \mathrm{kV}$, current of $25 \mathrm{~mA}$ being used.

The surface area and pore character of the catalysts were determined by nitrogen physisorption using an Autosorb IQ Station 1 (Quantachrome) device. Prior to measurement, the samples were outgassed at $473 \mathrm{~K}$ under vacuum for 2 hours.

Raman dispersion microscope (DXR) Thermo Scientific with the possibility of switching between macroscopic and microscopic analyses was used for Raman spectroscopy. The system operated with four types of lasers (455nm-blue, 532 $\mathrm{nm}$-green, $633 \mathrm{~nm}$ - red, $780 \mathrm{~nm}$ - NIR), being equipped with 10 fold magnifying Olympus lens.

\section{Reaction Mixtures Analyses}

Determination of hydrocarbons in the feed as well as in the hydrogenation product during the catalyst tests, was performed by GC method for which Agilent 7890 device, equipped with FID detector and HP PONA column (I.D. of $0,2 \mathrm{~mm}$, film thickness of $0,5 \mu \mathrm{m})$ was used. Following method parameters were applied: sample volume of $0.5 \mu 1$, injector temperature of $200^{\circ} \mathrm{C}, \mathrm{N} 2$ as carrier gas at the constant input pressure $(131.0 \mathrm{kPa})$, split ratio 100:1. Following oven temperature program was used: start at $35^{\circ} \mathrm{C}$, maintained for 15 minutes, then $2^{\circ} \mathrm{C} / \mathrm{min}$. increase to the value of $70^{\circ} \mathrm{C}$ then $10^{\circ} \mathrm{C} /$ to $250^{\circ} \mathrm{C}$, then $9,5 \mathrm{~min}$. isothermally.

\section{Testing of the Catalysts}

The catalysts prepared were tested by hydrogenation of C5 olefins mixture. A high pressure, electrically heated, stainless steel tubular reactor with ID of $400 \mathrm{~mm}, 1267 \mathrm{~mm}$ long, was used for this purpose. An axial temperature profile inside the reactor was measured by a set of 10 thermocouples placed in a $10 \mathrm{~mm}$ tube probe, which was located in the reactor axis. The catalyst layer was located in the middle section of the reactor, the catalyst being diluted by inert material $(\mathrm{SiC})$ in volume ratio 1:1 (weight ratio of catalyst vs. 
inert being 2.7:1). The whole amount of the catalyst $(10 \mathrm{~g})$ had been split into ten identical portions, each of them was then gradually put into the reactor, being every time overlaid by the same volume of the inert material.

\section{Results and Discussion}

\section{Catalyst Characterization}

\section{XRD Characteristics}

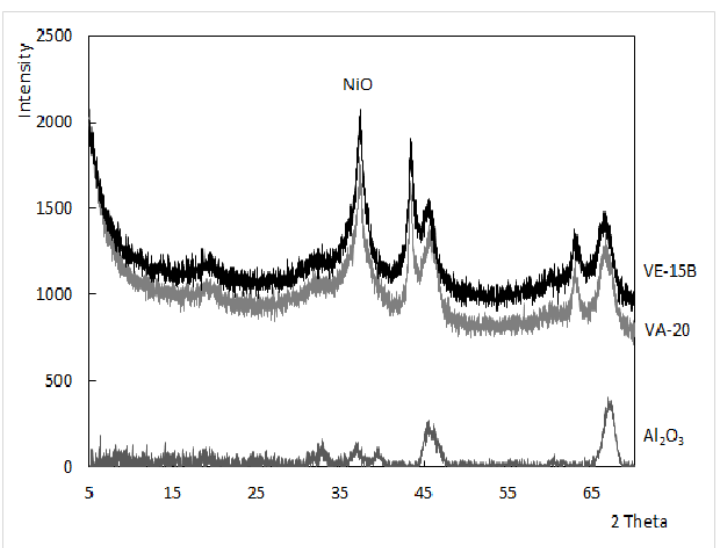

Figure 1. Diffraction patterns of Ni catalysts prepared with the use of different solvents and of $\Upsilon$-alumina used as the carrier
The annealed (oxidized) forms of catalysts were characterized by the XRD method. By this method, only two components were found in all samples: $\mathrm{NiO}$ and $\mathrm{Al} 2 \mathrm{O} 3$. Diffraction patterns of catalyst prepared by impregnation with the use of different solvents as well as that of pure alumina used for the samples preparation are shown in Figure 1.

\section{Raman Spectroscopy}

Raman spectra of both types of the egg-shell catalysts, i.e. catalysts impregnated by acetone solution (VA-20) or ethanol solution (VE-15B) respectively are shown in Figure 2.

The samples were analyzed with the use of $455 \mathrm{~nm}$ laser. As can be seen from Figure 2, both samples were characterized by main band at Raman shift of $1000 \mathrm{~cm}-1$, which is characteristic for $\mathrm{NiO}$. Nevertheless, there is another band in the spectrum of VE-15B (impregnated by the ethanol solution) in the range of 400 to $500 \mathrm{~cm}-1$ which by no means belongs to $\mathrm{NiO}$. It can be attributed to some kind of complex of $\mathrm{Ni}$ with nitrogen oxides. In this form, $\mathrm{Ni}$ is difficult to reduce, the reduction taking place only at very high temperature, considerably above the reduction temperatures characteristic for metal catalysts.

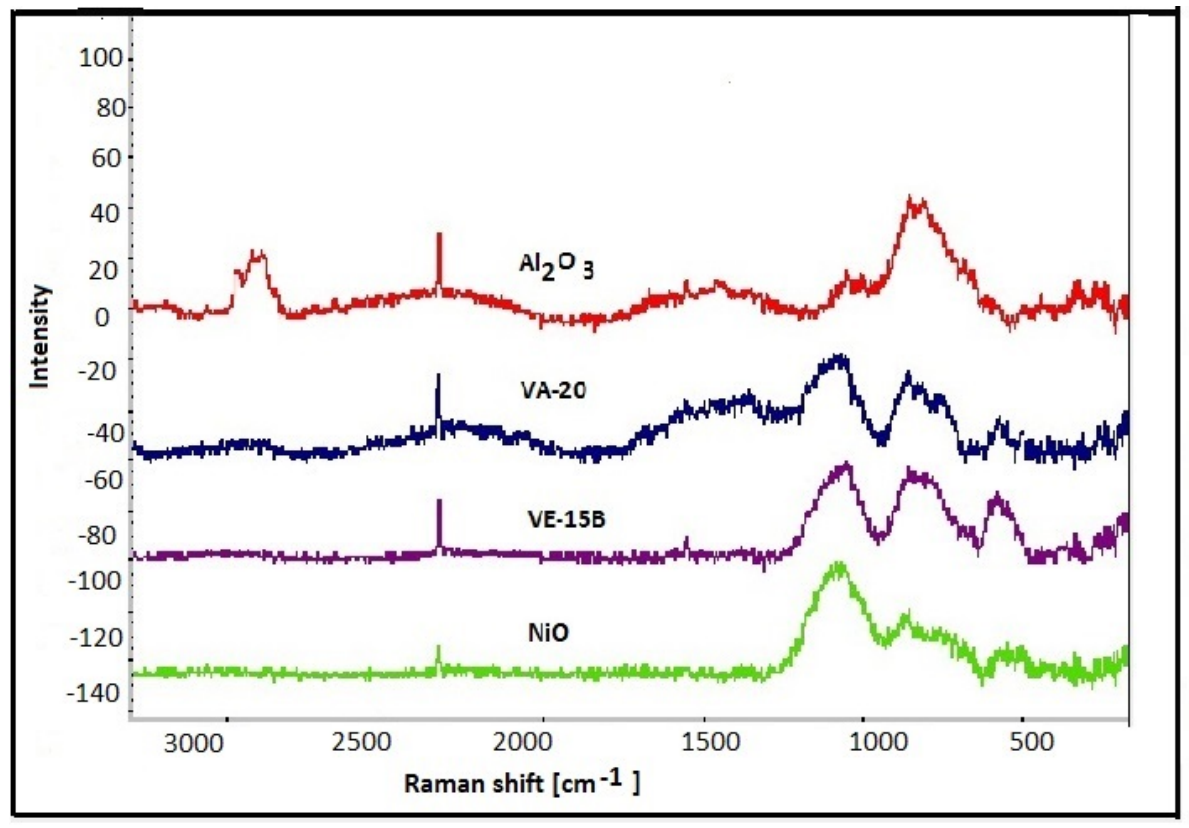

Figure 2. A comparison of Raman spectra of the catalyst VA-20, impregnated by acetone solution of Ni nitrate and the catalyst VE-15B impregnated by ethanol solution as well as pure $\mathrm{NiO}$ and alumina. Laser of wave length $450 \mathrm{~nm}$ was used. 


\section{Pore Size Distribution}

BET method was used to characterize the catalyst pore size and volume distributions. The adsorption isotherms for both types of Ni catalysts studied are shown in Figure 3 a,b.

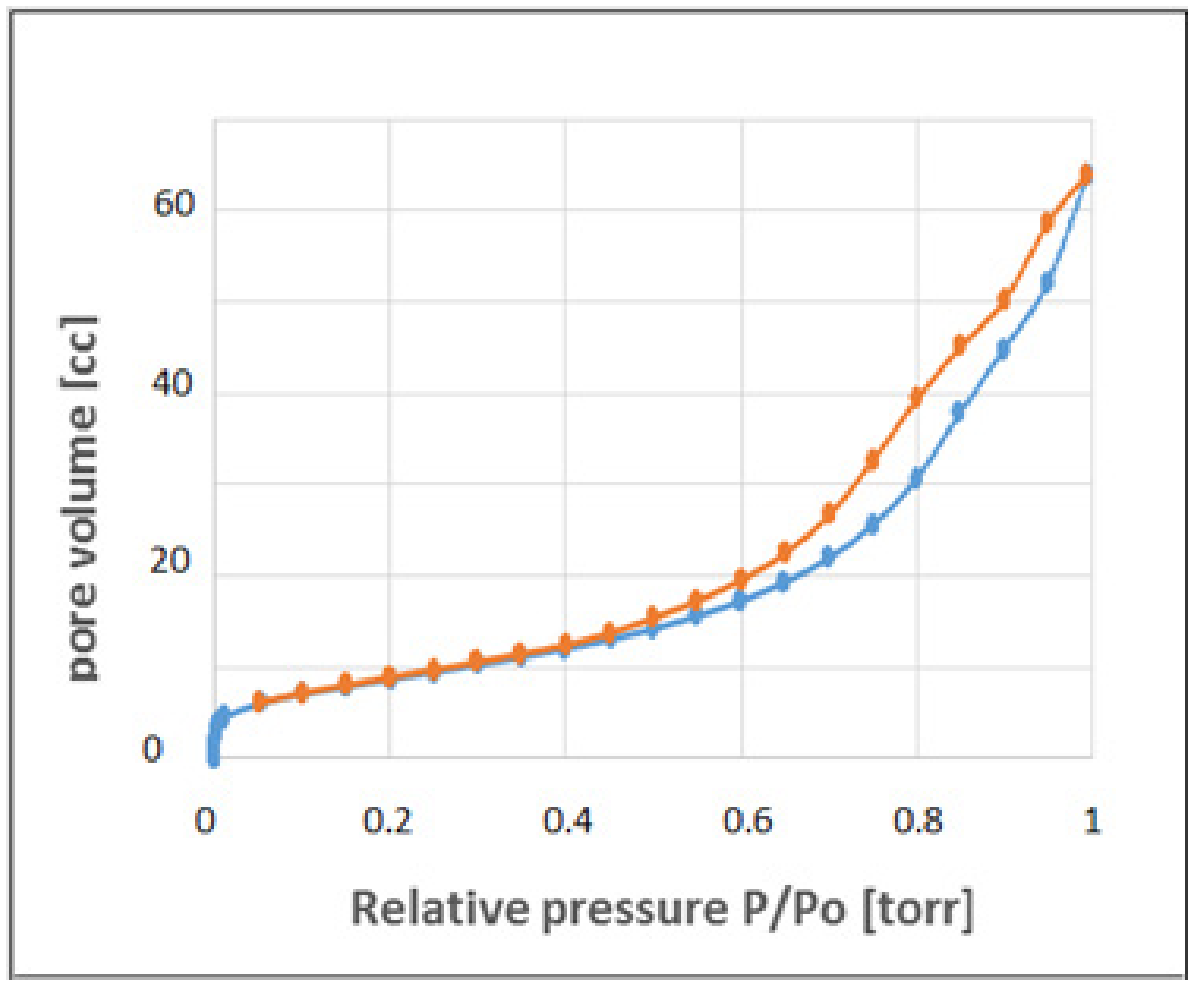

Figure 3a. Adsorption isotherms of catalyst VE-15B

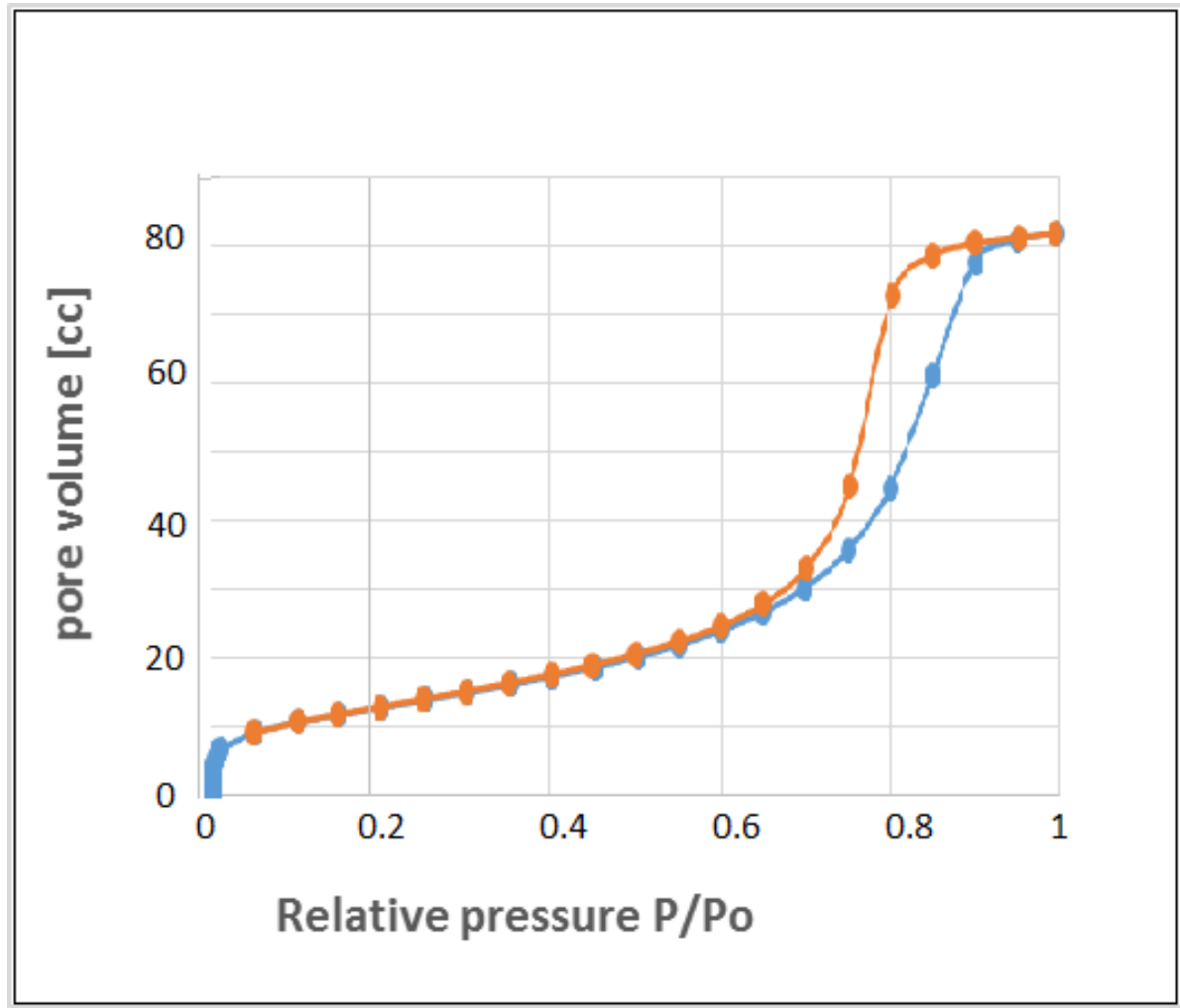

Figure 3b. Adsorption isotherms of catalyst VA-20. 
Also the pore size distribution (BET) shown by graphs in Figure 4a, b detects higher proportion of mesopores in VA-20 as well as a decrease of the whole pores volume during impregnation in case of VE-15B, i.e. when ethanol was used as the solvent.

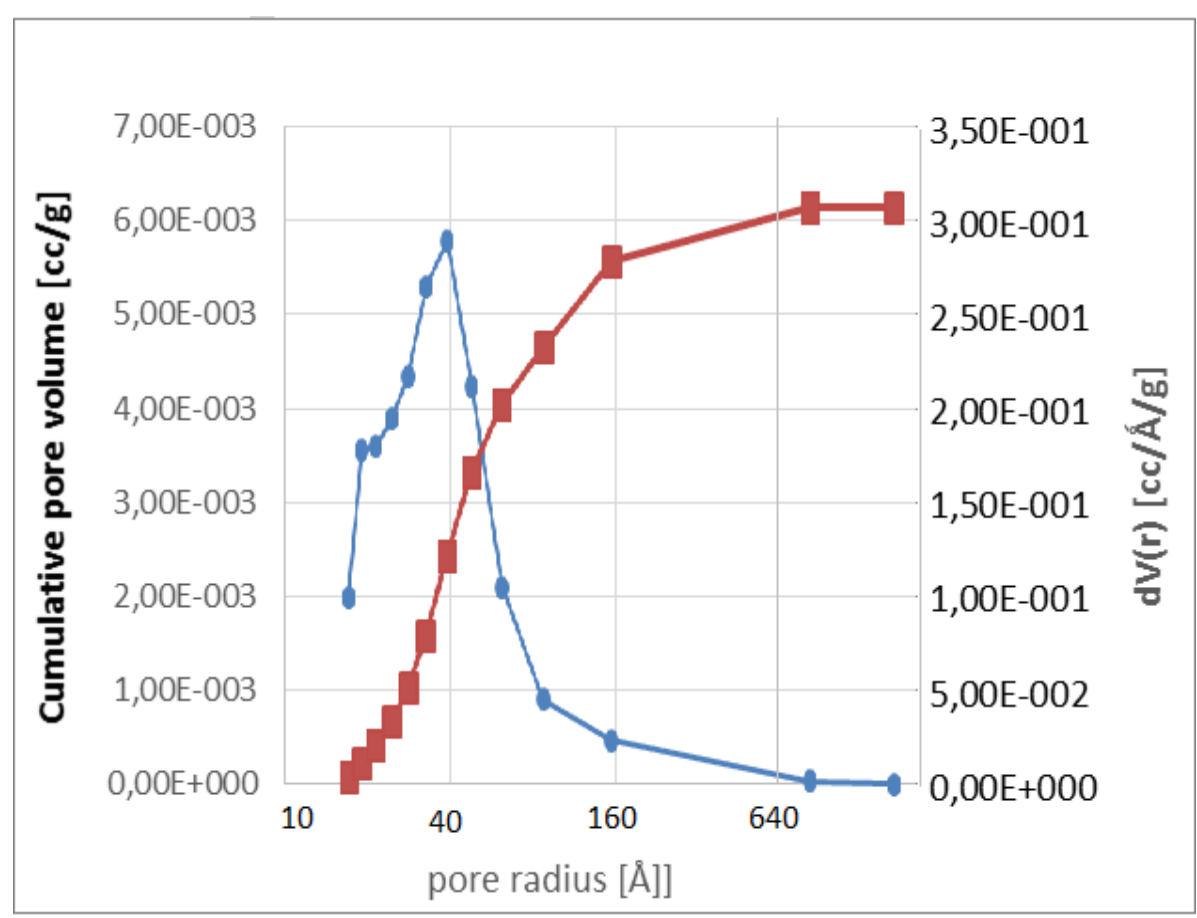

Figure 4a. BET characteristics of catalyst VE-15B.

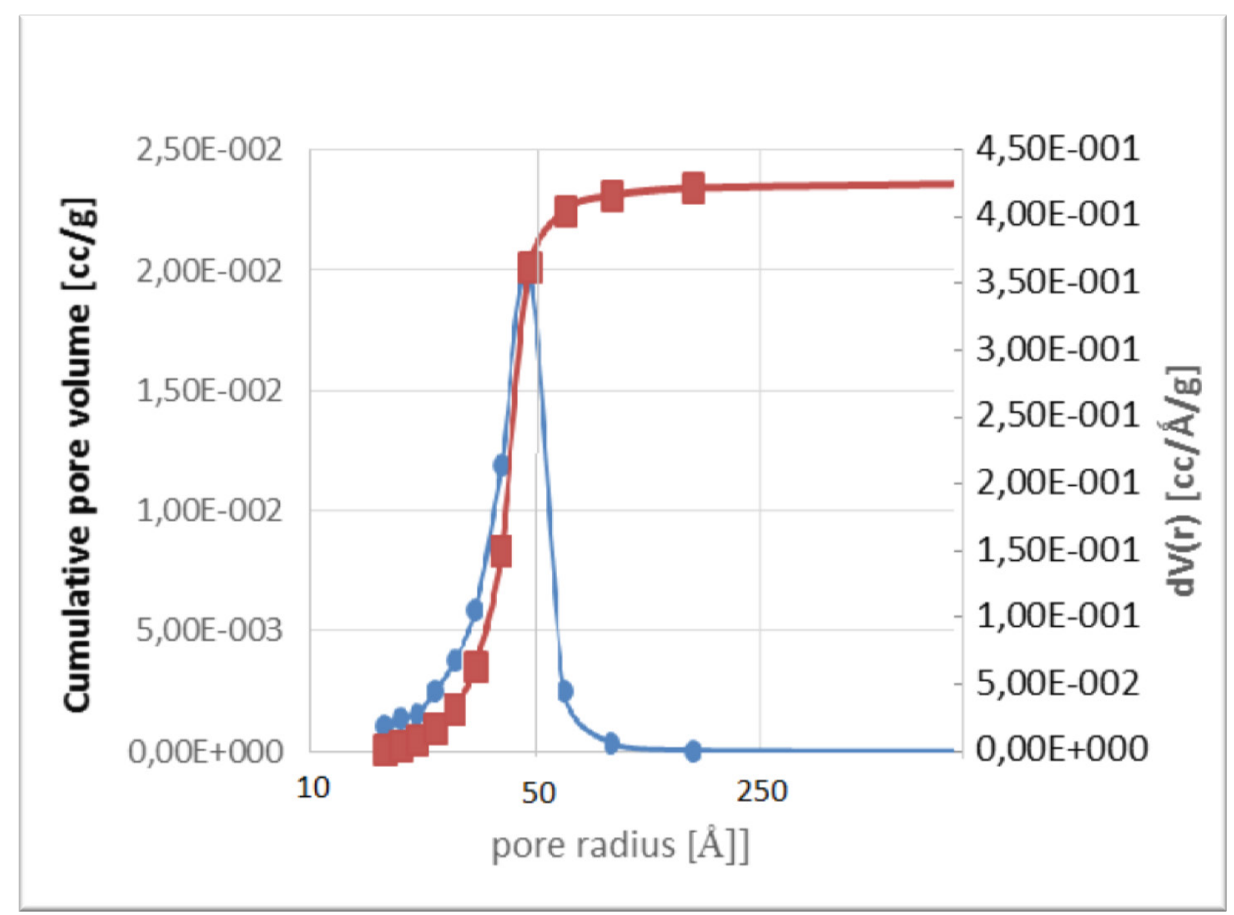

Figure 4b. BET characteristics of catalyst VA-20. 
(a)

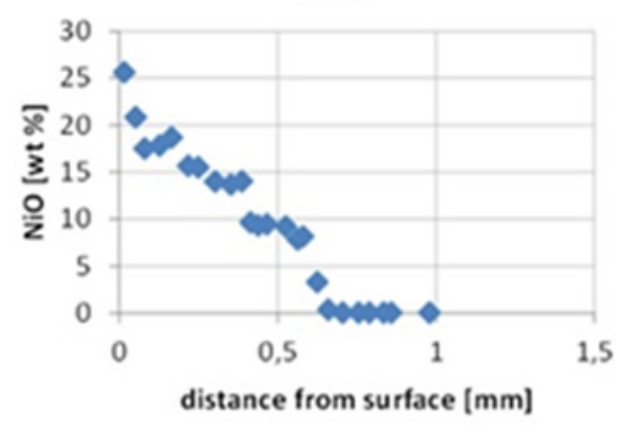

(b)

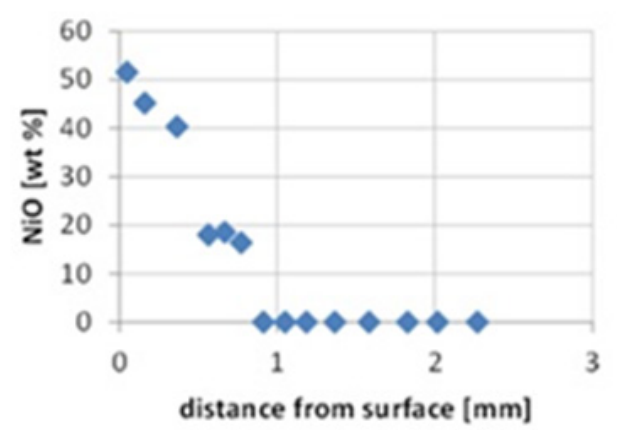

Figure 5. Internal profile of Ni concentration in particles of catalyst VA20 (a) and VE-15B (b)

The isotherm belonging to catalyst VA-20 can be characterized as classical hysteresis loop while the isotherm of catalyst VE-15B is deformed. The hysteresis loop indicates higher proportion of mesopores in entire pores volume when comparing it with VE-15B, impregnated by ethanol solution.

The internal surface area $(\mathrm{m} 2 / \mathrm{g})$ determined by $\mathrm{N}_{2}$ physisorption and evaluated by BET method was as follows: 128.4 for VA15B, 162.8 for VA20 and 172.4 for alumina used as the catalysts support. It is evident that saturation with Ni degraded the support area in some extent but not very substantially.

Internal $\mathrm{Ni}$ concentration profiles were measured by the EDS method. These profiles for the catalysts with highest $\mathrm{Ni}$ content, prepared with different solvents are shown in Fig. 5. It can be seen from the profiles that practically all $\mathrm{Ni}$ is concentrated in a layer less than $1 \mathrm{~mm}$ thick, so a catalysts of egg-shell type were really prepared though the shell thickness is higher than usual for commercial egg-shell catalysts containing noble metals. The maximum $\mathrm{Ni}$ concentration in the impregnated layer of VA 20 catalyst was of 25.5 mass \%. Whole amount of $\mathrm{Ni}$ was concentrated in a surface layer of thickness approx. $622 \mu \mathrm{m}$. As for VE-15B catalyst, the maximum $\mathrm{Ni}$ concentration in the surface layer (thickness $720 \mu \mathrm{m}$ ) was $51.5 \mathrm{mass} \%$.

\section{Testing of the Catalysts}

The egg-shell catalysts were tested in the process of hydrogenation of C5 fraction from steam cracking in which major part of originally present dienes, had been converted into alkenes by a standard plant operation - selective hydrogenation. The composition of the fraction used for the testing can be seen from Table 2 .

The values of conversion of individual alkenes to alkanes were taken as the catalyst activity criteria. As industrial C5 fraction is a rather complex mixture containing almost all $\mathrm{C} 5$ alkenes possible, a comparison is presented (see Figures 6 to 8) for 1-pentene and 2-methyl-2-butene as representatives, 1 -pentene representing highly reactive alkene present in low concentration while 2-methyl-2-butene being the least reactive alkene present in highest concentration.

Table 2. Composition of $\mathrm{C} 5$ fraction used as the feedstock in catalyst testing

\begin{tabular}{|c|c|c|c|}
\hline Compound & $\mathrm{w} \%$ & Compound & $\mathrm{w} \%$ \\
\hline n-butane & 0.27 & 2-methyl-1,3- butadiene & 0.53 \\
\hline$\Sigma \mathrm{C} 4$ alkenes & 0.76 & trans -2-pentene & 9.18 \\
\hline 3-methyl-1-butene & 0.55 & cis-2-pentene & 2.83 \\
\hline i-pentane & 11.78 & 2-methyl-2-butene & 19.53 \\
\hline i-propanol+2-butine & 0.02 & 3-methyl-1,2-butadiene & 1.06 \\
\hline 1-pentene & 1.16 & $\begin{array}{c}\text { cyclopentene + } \\
\text { 3-methyl-1-pentene }\end{array}$ & 6.94 \\
\hline 2-methyl-1-butene & 4.73 & cyclopentane & 20.62 \\
\hline n-pentane & 19.45 & C6+ & 0.59 \\
\hline
\end{tabular}

A comparison of activity values and their dependence on the test time, of two catalyst impregnated by ethanol solution of Ni salt is shown in Figure 6. 


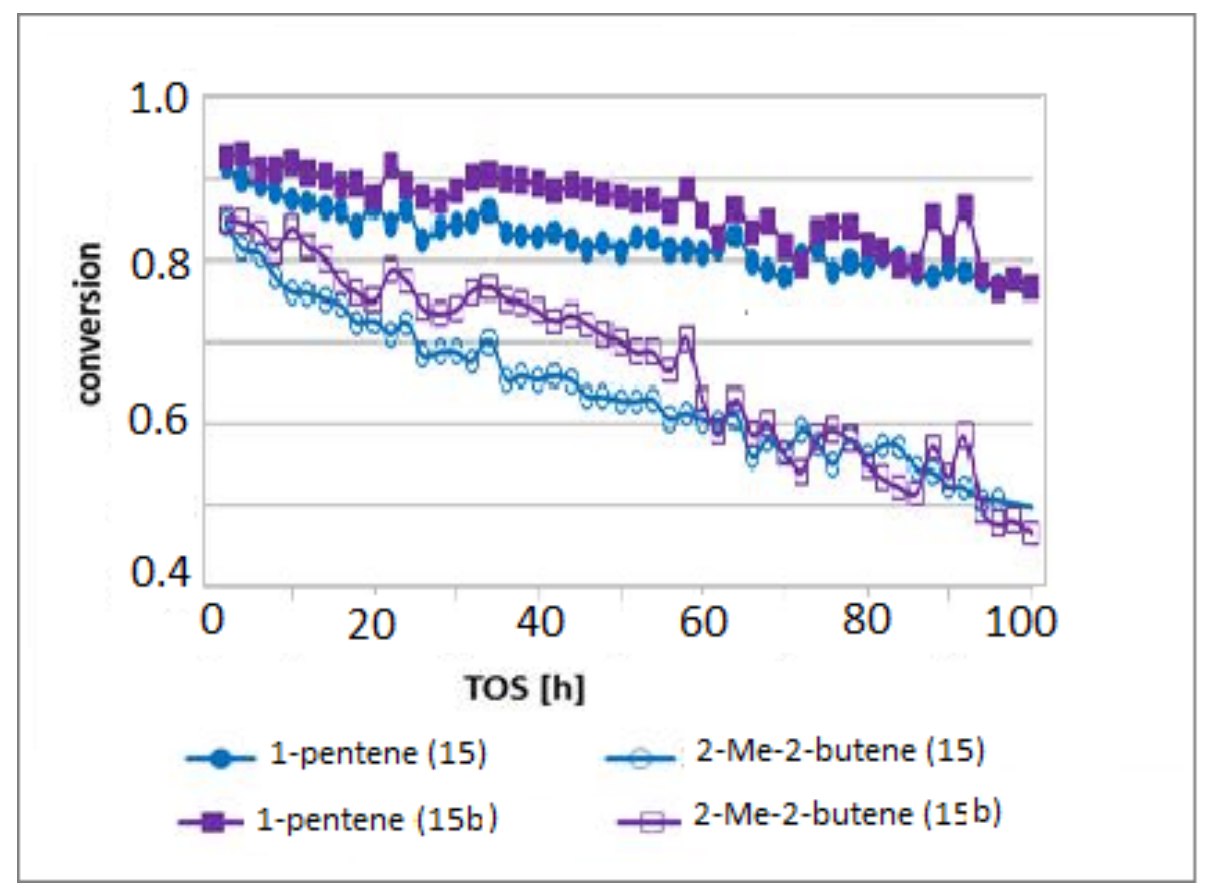

Figure 6. Dependence of 1-pentene and 2-methyl-2-butene values on TOS for VE-15 and VE-15B catalysts. Hydrogenation conditions: input temperature $100^{\circ} \mathrm{C}$, pressure $2 \mathrm{MPa}, \mathrm{H} 2$ /hydrocarbons $=6.5$

The catalyst VE-15 had Ni content of 10.9 mass \% while the Ni content in VE-15B was 20.9 mass \%. Different Ni content values were achieved by application of different numbers of the impregnation- cycles in the catalysts preparation process.

Despite the fact that the catalyst VE-15B contained almost twice as much $\mathrm{Ni}$ in comparison with VE-15, the initial values of alkene conversion over both of these catalysts were practically identical and so was their dependence on the time of the experiment. For this pair of catalysts, no influence of $\mathrm{Ni}$ content, both on the starting activity and the velocity of its decrease in the course of time, was observed. It can be concluded that from certain amount of Ni further increase of $\mathrm{Ni}$ concentration doesn't lead to an increase of active centers available for the reaction mixture.

The same experiments were made with another pair of catalysts, in this case with those prepared by impregnation with acetone solution of $\mathrm{Ni}$ salt. Also these catalysts contained different amount of Ni. (see Table 1). Different Ni content values were achieved by application of different number of the impregnation cycles in the catalysts preparation process. The results of the $100 \mathrm{~h}$ lasting test are shown in Figure 7.

Similarly to previous case, in which the catalysts impregnated with ethanol solution were used, no substantial difference in activity of both catalysts was observed. Also the velocity of the activity decrease was approx. the same for both of these catalysts. It can be stated also for the catalyst impregnated by acetone solution, that no influence of $\mathrm{Ni}$ content, both on the starting activity and the velocity of the activity decrease in the course of time, was observed in said concentration range.

A comparison of test results obtained with catalysts prepared by impregnation with the use of different solvents is shown in Figure 8. Unfortunately, impregnation by the same method, with the solution of the same $\mathrm{Ni}$ salt concentration but different solvents resulted in different final $\mathrm{Ni}$ concentration in the catalyst. Therefore the tests of catalysts containing different $\mathrm{Ni}$ amount must have been compared. These catalysts were: VE-15B and VA-20 (see Table 1). As discussed above, Ni concentration in this range had no influence on catalyst activity, the test comparison can be therefore considered representative.

Though the catalyst impregnated with the use of ethanol solution (VE-15B) contained higher amount of $\mathrm{Ni}$, its initial activity was lower and its activity decrease during the first $100 \mathrm{hrs}$ of experiment was considerably faster in comparison with the catalyst prepared with the use of acetone solution (VE-15B).

It is apparent both from the characteristics by special analytical methods and the test results, that there are differences between catalysts prepared by the same impregnation method but with the use of different solvents. The nature of the solvent influences the active layer thickness and, most probably, the form and $\mathrm{Ni}$ crystals character on the carrier surface. Both catalysts differ also in pore volume. Obviously, the impregnation with ethanol solution leads to mezopores volume decrease, which is most probably the main reason of lower activity of the catalyst.

Impregnation with acetone solution of $\mathrm{Ni}$ salt gave catalyst with higher activity, the activity however also decreasing in some extent during the first $100 \mathrm{hrs}$ of a test. To investigate the catalyst stability, a long lasting test with said catalyst was performed. Its result can be seen from Figure 9. It is evident from the figure that after a long period 
of time, more than $200 \mathrm{~h}$, the activity was stabilized and remained constant for more than another $200 \mathrm{~h}$. Also differences in reactivity among particular $\mathrm{C}_{5}$ alkenes can be clearly seen from Figure 9 . It decreased in the order cyclopentene $>1$-pentene $=$ cis- 2 -pentene $=$ trans-2-pentene $>$ 2-methyl-1-butene $>2$-methyl-2-butene.

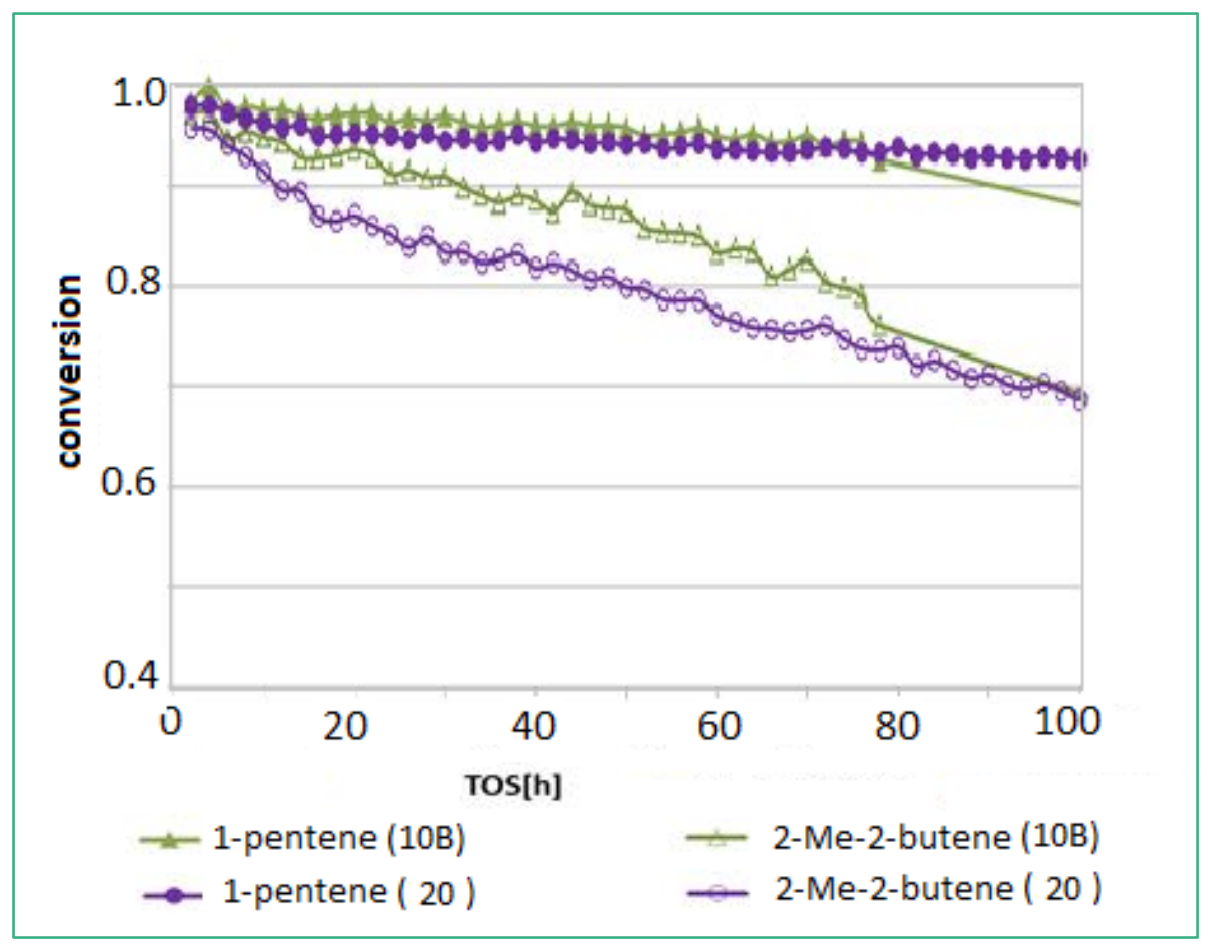

Figure 7. Time dependence of conversions of 1-pentene and 2-methyl-2-butene concentrations during hydrogenation on VA10B (Ni, ethanol solution) and VA20 (Ni acetone solution). Input temperature of $100^{\circ} \mathrm{C}$, pressure $2 \mathrm{MPa}, \mathrm{H}_{2} /$ hydrocarbons $=6.5$.

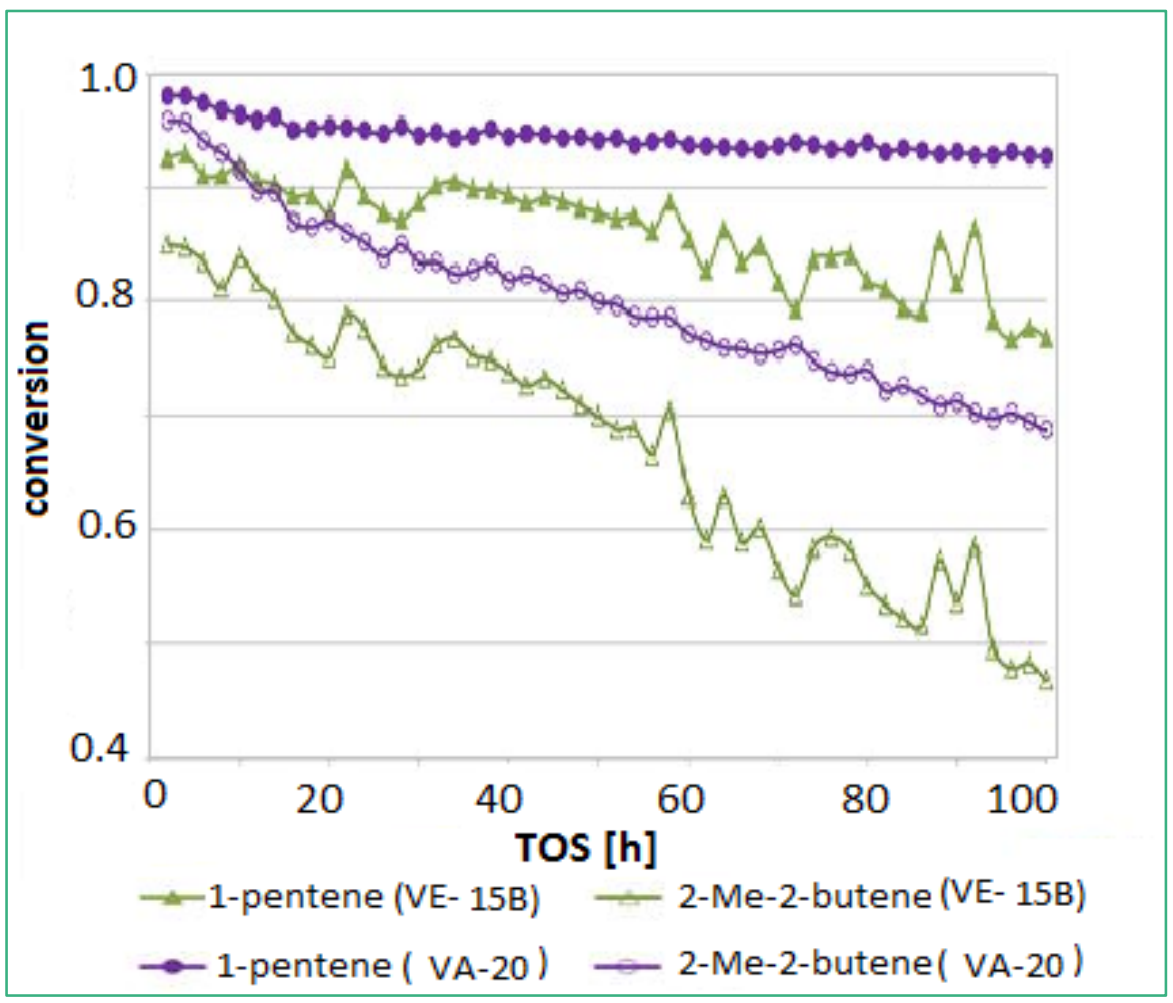

Figure 8. Comparison of activities of catalysts prepared by impregnation with the use of different solvents: VA-20 (acetone solution), VE-15B (ethanol solution). Testing conditions: input temperature $100^{\circ} \mathrm{C}$, pressure $2.0 \mathrm{MPa}, \mathrm{H} 2 /$ hydrocarbons $=6.5$. 


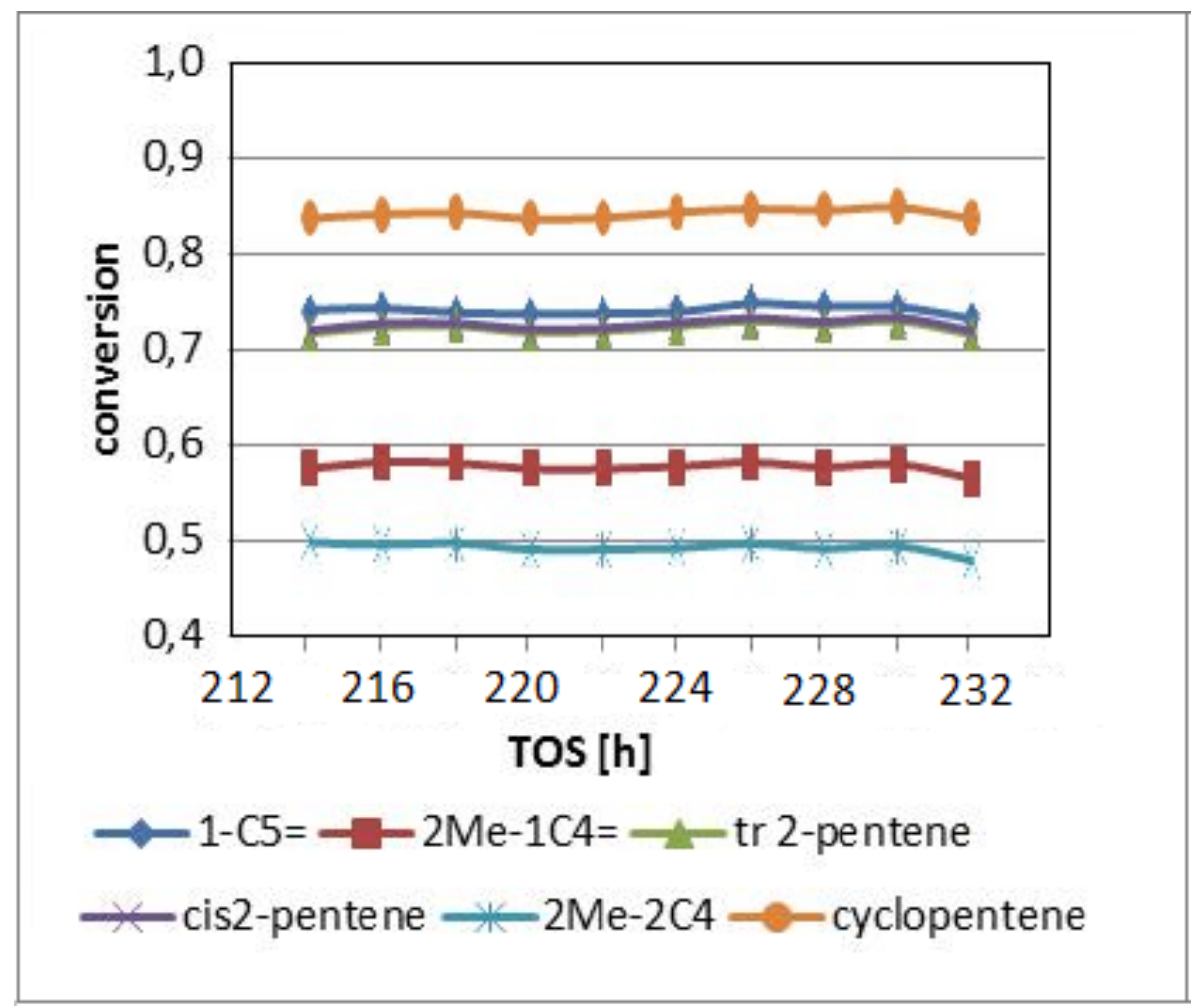

Figure 9. Dependence of all olefins conversions on time on stream (TOS) for VA-20 catalyst at $2 \mathrm{MPa}$ and the input temperature of $100{ }^{\circ} \mathrm{C}$ and $\mathrm{H} 2$ /hydrocarbon molar ratio of 6.5

\section{Conclusions}

$\mathrm{Ni} / \gamma$-alumina, egg-shell type catalysts were prepared by the wet impregnation method, organic solution of Ni nitrate being used in this process. Ethanol and acetone proved to be suitable solvents for this purpose so that thin active layer catalysts were obtained. Nevertheless, the catalyst characteristics, as well as their activities in the hydrogenation of $\mathrm{C}_{5}$ alkenes mixture differed in dependence on the solvent used for the impregnation. Different solvents used for impregnation contribute to different composition of oxidized phase in the calcined form of catalyst as was proved by Raman spectroscopy. The solvent also influences the pore volume, most significantly in the mezopores range, which also has an impact on the catalyst activity.

The preparation of Ni- based egg-shell catalyst by the wet impregnation of alumina particles with organic solutions of Ni nitrate proved to be an effective method of the production of industrially applicable hydrogenation catalyst which can be successfully used for hydrogenation of real petrochemical mixtures of olefins, like $\mathrm{C}_{5}$ fraction isolated from pyrolysis gasoline.

\section{Acknowledgements}

The publication/presentation/another result is a result of the project Development of the UniCRE Centre (Project Code LO1606) which was financially supported by the
Ministry of Education, Youth and Sports of the Czech Republic under the National Program for Sustainability I.

\section{REFERENCES}

[1] Chinese Petrol. Comp., Eggshell catalyst and process for preparing of the same. GB 2310384A, 1996.

[2] Coleto I., et al. (). Valorization of $\alpha$-olefins: Double bond shift and skeletal isomerization of 1-pentene and 1-hexene on zirconia-based catalysts. Catalysis Today, 149, 275-280, 2010 .

[3] Goossens E., Donker R., van der Brick F., Reactor runaway in pyrolysis gasoline hydrogenation. Studies in Surface Science and Catalysis 106, 245-254, 1997.

[4] Magyar S., Hancsók J., Kalló D., Reactivity of several olefins in the HDS of full boiling range FCC gasoline over PtPd/USY. Fuel Processing Technol., 89, 736-739, 2008.

[5] Pawelec B., et al., Carbon-supported tungsten and nickel catalysts for hydrodesulfurization and hydrogenation reactions. Appl. Catalysis A, 206,295-307, 2001.

[6] Simakova I.L., Simakova O.A., Romanenko A.V., Murzin D. Y., Hydrogenation of Vegetable Oils over $\mathrm{Pd}$ on Nanocomposite Carbon Catalysts. Industrial and Eng. Chem. Research, 47; 7219-7225, 2008.

[7] Wen X., et al., An egg-shell type Ni/Al2O3 catalyst derived from layered double hydroxides precursor for selective hydrogenation of pyrolysis gasoline. Appl. Catal A; General 
468; 204-215, 2013.

[8] Regalbuto J.: Catalyst Preparation Science and Engineering 343 -360; CRC Press, Boca Raton, London, New York (2007).

[9] Lekhal A., Glasser B.J., Johannes G. Khinast J. G.: Impact of drying on the catalyst profile in supported impregnation catalysts; Chemical Engineering Science 56, 15, 4473-4487 (2001)
[10] Li W.D., Li Z.F., Qin Z.F., Chen S.Y.: Theoretical prediction and experimental validation of the egg-shell distribution of $\mathrm{Ni}$ for supported Ni/Al20O3 catalysts; Chemical Engineering Science,49, 24, 4889-4895 (1994)

[11] Silva $H$. et al.: Synthesis and characterization of $\mathrm{Fe}-\mathrm{Ni} / \mathrm{y}-\mathrm{A} 12 \mathrm{O} 3$ egg-shell catalyst for $\mathrm{H} 2$ generation by ammonia decomposition; Applied Catalysis A: General, Volume 505, 548-556 (2015). 